\title{
SIMULATION ANALYSIS FOR QOS IN INTERNET OF THINGS WIRELESS NETWORK
}

Ghaith Mojib

Faculty of Information Science and Technology, National University of Malaysia.

Selangor (Malaysia).

E-mail: ghaith.alkhazraje@gmail.com

Azana Hafizah Mohd Aman

Senior Lecturer, Faculty of Information Science and Technology, National University of

Malaysia. Selangor (Malaysia).

E-mail: azana@ukm.edu.my

Mahdi Khalaf

Faculty of Information Science and Technology, National University of Malaysia.

Selangor (Malaysia).

E-mail:m1a2h3d4i5.mh@gmail.com

Rosilah Hassan

Associate Professor, Faculty of Information Science and Technology, National University of Malaysia. Selangor (Malaysia).

E-mail: rosilah@ukm.edu.my

Recepción: 29/07/2019 Aceptación: 18/09/2019 Publicación: 06/11/2019

\section{Gitación sugerida:}

Mojib, G., Aman, A.H.M., Khalaf, M. y Hassan, H. (2019). Simulation analysis for QoS in Internet of Things wireless network. 3C Tecnología. Glosas de innovación aplicadas a la pyme. Edición Especial, Noviembre 2019, 77-83. doi: http://dx.doi.org/10.17993/3ctecno.2019. specialissue $3.77-83$

\section{Suggested citation:}

Mojib, G., Aman, A.H.M., Khalaf, M. \& Hassan, H. (2019). Simulation analysis for QoS in Internet of Things wireless network. 3C Tecnología. Glosas de innovación aplicadas a la pyme. Special Issue, November 2019, 77-83. doi: http://dx.doi.org/10.17993/3ctecno.2019. specialissue 3.77-83 


\section{ABSTRACT}

The Internet of things (IoT) composed of numerous smart devices and communication technologies. The IoT devices interchange the information through wireless or wired network connections. Compared to the wired connection, the wireless connection in IoT is the current primary concern. In general, there are few wireless network protocols that can be used to connect smart devices such as 6LoWPAN, RPL, CoAP, MQTT, and AMQP. These protocols are used to transfer messages in the IoT network. This paper, compared IPv6 protocol wireless network, Low Power Wide Area Network (6LoWPAN) and Low Power and Lossy Network Routing (RPL) for IoT communications using Contiki:cooja simulator. The considered QoS parameters are throughput, end-to-end delay, and jitter. Based on the results, 6 LoWPAN achieved better QoS compared to RPL.

\section{KEYWORDS}

6LoWPAN, RPL, Simulation, Throughput, End-to-End Delay, Jitter. 


\section{INTRODUCTION}

Internet of Thing (IoT) system uses low power sensors and microcontrollers. The LoWPAN which known as Low Power Wide Area Network is the first IoT network that deploys many sensors and controllers linked into internet network. Since the network is using IPv6 protocol, thus the name of the IoT network under Internet Protocol Version 6 (IPv6). Ahmed (2017) and Aman (2016) is called 6LoWPAN (IPv6 over Low-Power Wireless Personal Area Networks) (Li, 2018). Another network that supports IoT system is called RPL (IPv6 Low-Power and Lossy Network Routing Protocol). RPL divides packet processing and adapt routing optimization objects, including energy consumption, communication delays and limits minimization (Parasuram, 2016). Multiple times of RPL can run simultaneously within the network (Kim et al. 2017).

\section{RESEARCH METHODOLOGY}

This research focused on the study of the Quality of Service (QoS) scenarios for IoT in 6LowPAN and RPL. This work assumes that the infrastructure developed supports 6LoWPAN and RPL architecture. The evaluation is done using Contiki: cooja network simulator. The Contiki: cooja is programmed so that the limited node speed is 200 as in (Xie et al., 2014). Also, the number of nodes varied from 10 to 50 nodes. The research metrics are shown in Table 1.

Table 1. Simulation Parameters General.

\begin{tabular}{|c|c|}
\hline Parameter & Value \\
\hline Node transmission range & $50 \mathrm{~m}$ \\
\hline Node carrier sensing range & $100 \mathrm{~m}$ \\
\hline Distribution of nodes & Random \\
\hline Routing protocol & 6LowPAN, RPL \\
\hline Mote type/startup delay & T-mote sky/1000ms \\
\hline MAC layer & CSMA/CA \\
\hline Bitrate & 250 kbps \\
\hline
\end{tabular}




\section{Parameter}

Mote type/startup delay

\section{Value}

T-mote sky/200ms

\section{RESULTS AND DISCUSSION}

The parameters considered for this paper are throughput (Aman, 2016), end-to-end delay (Hassan \& Jabbar, 2017) and jitter. Graphic 1 shows the results for throughput, Graphic 2 shows the results for end-to-end delay, finally Graphic 3 shows the results for jitter.

\section{Throughput}

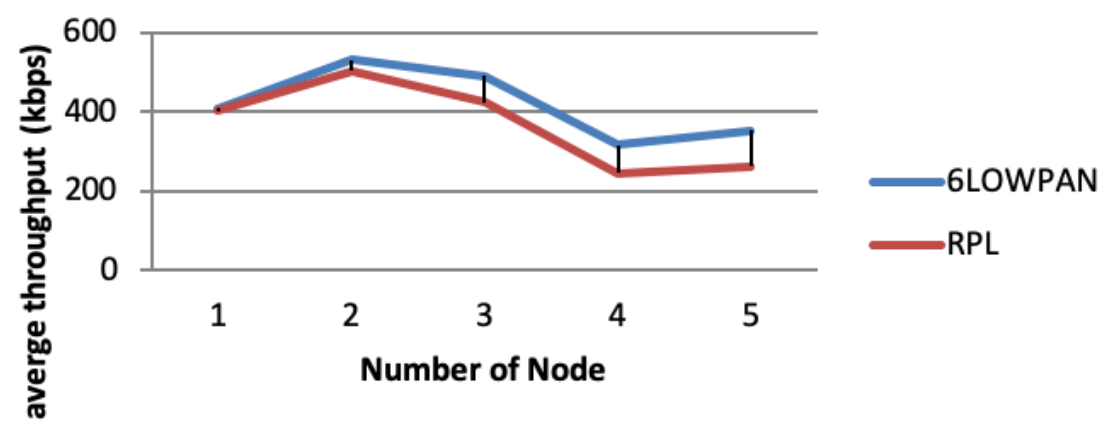

Graphic 1. Average Throughput Number of Nodes.

\section{e2e Delay}

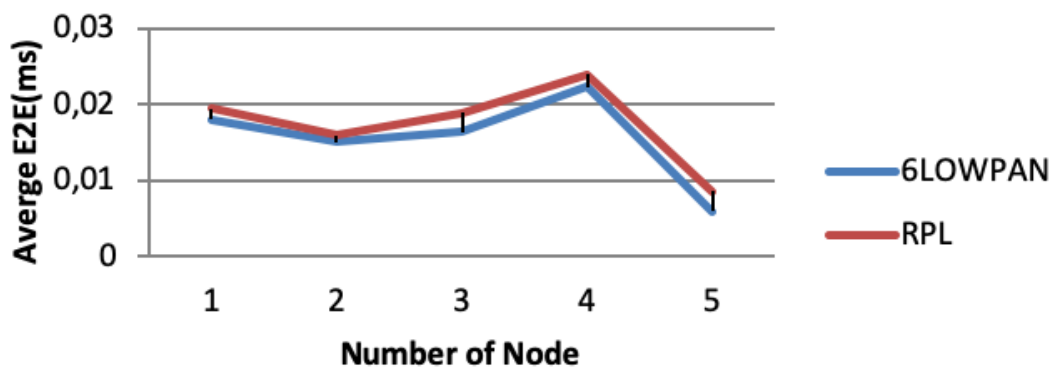

Graphic 2. End-to-end Delay Number of Nodes. 


\section{Jitter}

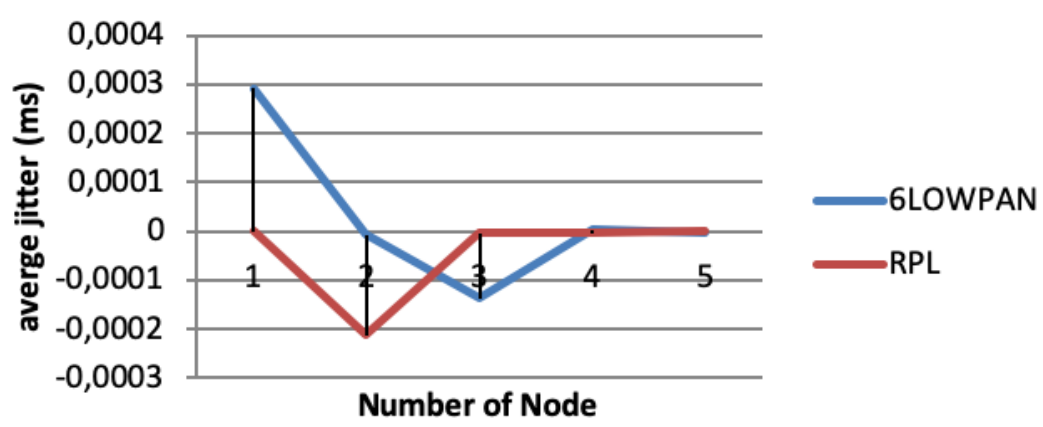

Graphic 3. Jitter Number of Nodes.

The average throughput from Graphic 1 shown at a data rate of $250 \mathrm{kbps}$, 6LoWPAN, RPL, and is slightly different from the selected number of nodes because the topology has changed during simulation. The average overall capacity of the two is mainly $3907 \mathrm{Kbps}$ or $3907 \mathrm{Mbps}$. Note that for both routing protocols, the number of nodes affected. Different routing tables over several nodes result from the random movement of nodes, which results in the fluctuation of the received average throughput. For RPL $2.57 \%$ and 6LoWPAN, 2.14\% is the difference between the highest throughput and the average throughput of the other Nodes, which indicates a different number of nodes impact significantly the average throughput, the 6LoWPAN has better throughput compared with RPL.

Graphic 2 shows the end-to-end delay of 6LoWPAN and RPL routing protocols. A distinct amount of nodes have no significant effects since each RPL node can keep a routing table that saved all data regarding current paths but 6LoWPAN sets the road on demand. That means the average end-to-end RPL is not much more effective compared to 6LoWPAN for some nodes chosen than for some.

Graphic 3 represents the variation in jitter. Jitter signifies a difference in delay with which packets reach the destination. Although the variety is almost same but on average 6LoWPAN performs well in terms of jitter compared to RPL. It shows that, if the nodes are higher, the RPL is less than 6LoWPAN. 


\section{ACKNOWLEDGEMENT}

The authors are grateful to Faculty of Information Science and Technology, National University of Malaysia. This research is also funded by research grant DIP-2018040 .

\section{CONCLUSIONS}

The Internet of Things considered as one of the most significant changes to the current innovation these days. By analyzing the QoS of IoT in 6LoWPAN and RPL, many features revealed to prove its suitability for IoT. Link layer of 6LoWPAN and RPL could support tiny things to participate. Protocol stack for both is appropriate for IoT. Nevertheless, 6LoWPAN yield marginally better results than RPL.

\section{REFERENCES}

Ahmed, A. S, Hassan, R., \& Nor, E. O. (2017). Securing IPv6 Link Local Communication Using IPSec. Obstacles and Challenges. Advanced Science Letters, 23(11), 11124-11128. doi: https://doi.org/10.1166/asl.2017.10234

Aman, A. H. M., Hashim, A. H. A, Abdullah, A., Ramli, H. A. M, \& Islam, S. (2016). Multicast Support in Network Based Mobility Management: Current Challenges and Solutions. Advanced Science Letters, 22(10), 2794-2798. doi: https:/ / doi.org/10.1166/asl.2016.7123

Aman, A. H. M., Hashim, A. H. A, Abdullah, A., Ramli, H. A. M, \& Islam, S. (2016). Evaluation of an Enhanced Multicast Data Flow Technique in Network Mobility. International Journal of Future Generation Communication and Networking, 9(7), 153-164. doi: http://dx.doi.org/10.14257/ijfgcn.2016.9.7.15

Aman, A. H. M., Hashim, A. H. A, Abdullah, A., Ramli, H. A. M., \& Islam, S. (2016). Parametric Comparison of Multicast Support for Network Mobility Management: A Qualitative Analysis. International Journal of Multimedia and Ubiquitous Engineering, 11(9), 203-210. doi: https://doi.org/10.14257/ ijmue.2016.11.9.21 
Hassan, R., \& Jabbar, R. (2017). End-to-end (e2e) Quality of Service (QoS) for IPv6 Video Streaming. 19th International Conference on Advanced Communication Technology (ICACT), 1-4, South Korea. doi: https://doi.org/10.23919/ ICACT.2017.7890045

Kim,H.S., Kim, H., Paek,J. \& Bahk,S. (2017).Load Balancing under Heavy Traffic in RPL Routing Protocol for Low Power and Lossy Networks. IEEE Transactions on Mobile Computing. doi: https://doi.org/10.1109/TMC.2016.2585107

Li, S., Xu, L. Da \& Zhao, S. (2018). 5G Internet of Things: A survey. Fournal of Industrial Information Integration, 10, 1-9. doi: https://doi.org/10.1016/j. jii.2018.01.005

Österlind, F., Dunkels, A., Eriksson, J., Finne, N. \& Voigt, T. (2006). Crosslevel sensor network simulation with COOJA. Proceedings-Conference on Local Computer Networks, LCN 641-648. doi: https://doi.org/10.1109/LCN.2006.322172

Parasuram, A., Culler, D. \& Katz, R. (2016). An Analysis of the RPL Routing Standard for Low Power and Lossy Networks. Retrieved from: http://digitalassets.lib.berkeley. edu/techreports/ucb/text/EECS-2016-106.pdf

Xie, H., Zhang, G., Su, D., Wang, P. \& Zeng, F. (2014). Performance evaluation of RPL routing protocol in 6lowpan. Proceedings of the IEEE International Conference on Software Engineering and Service Sciences, ICSESS, 625-628. doi: https://doi. org/10.1109/ICSESS.2014.6933646 